Article

\title{
Form-Finding of Funicular Geometries in Spatial Arch Bridges through Simplified Force Density Method
}

\author{
Juan José Jorquera-Lucerga \\ Department of Civil Engineering, Technical University of Cartagena, 30203 Cartagena, Spain; \\ juanjo.jorquera@upct.es; Tel.: +34-868-071277
}

Received: 25 October 2018; Accepted: 3 December 2018; Published: 10 December 2018

check for updates

Featured Application: The paper presents a simplified method with potential application to find the funicular form either at the conceptual design or final stage of design of arch bridges.

\begin{abstract}
In a "classical" vertical planar arch bridge subjected only to in-plane loads, its funicular geometry (which is the geometry that results in an equilibrium state free from bending stresses, i.e., simply under axial forces) is contained within a vertical plane. In the so-called "spatial arch bridges," their structural behavior extends from the essentially vertical in-plane behavior of the "classical" arch bridges to a three-dimensional behavior. The paper presents how the Force Density Method, which is a form-finding method originally developed for cable meshes, can be simplified to easily obtain three-dimensional funicular arches. The formulation and flow chart of the method is presented and discussed in detail within this paper. Additionally, some case studies illustrate its scope. This paper intends to be useful at the conceptual stage of bridge design when the three-dimensional geometry for the spatial arch bridge typology is considered either because of functional requirements, structural efficiency, or for aesthetical purposes.
\end{abstract}

Keywords: spatial arch bridge; funicular; form-finding; force density method

\section{Introduction}

\subsection{Spatial Arch Bridges and Funicularity}

The structural behavior of spatial arch bridges, which is a concept introduced for the first time in Reference [1], extends from the essentially vertical in-plane behavior of the "classical" arch bridges to three-dimensional behavior [1,2]. This structural type was pioneered by the Ziggenbach, Landquart, Bohlbach, and Schwandbach deck-stiffened spatial arch bridges built between 1924 and 1933 and designed by Robert Maillart who was clearly ahead of his time [3,4]. This spatial behavior emerges because the arch is subjected to out-of-plane loads. For example, when the arch springings and the deck abutments do not coincide (as in the Hulme Arch in Manchester, see Figure 1 and Reference [5]), when the deck is curved in a plane (as in the Gateshead Footbridge, see Figure 2 and Reference [6]) or when the arch is rotated about either a longitudinal position (as in the York Millennium Bridge (see Figure 3 and Reference [7] or in the La Devesa footbridge [8]) or a vertical axis (as in the Juscelino Kubitschek Bridge [9]). 


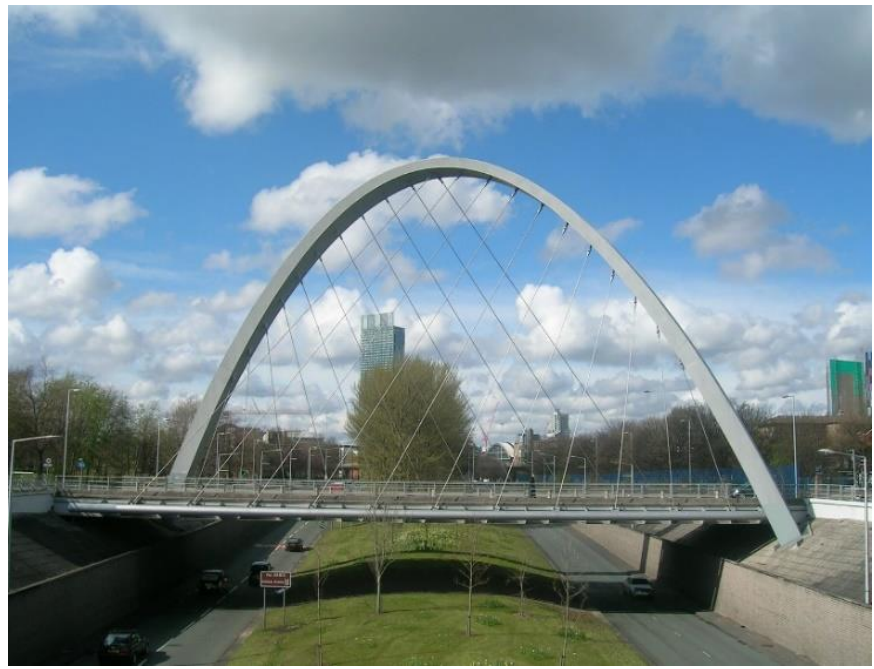

Figure 1. Hulme Arch (Photo: https:/ / www.flickr.com/photos/raver_mikey Creative Commons).

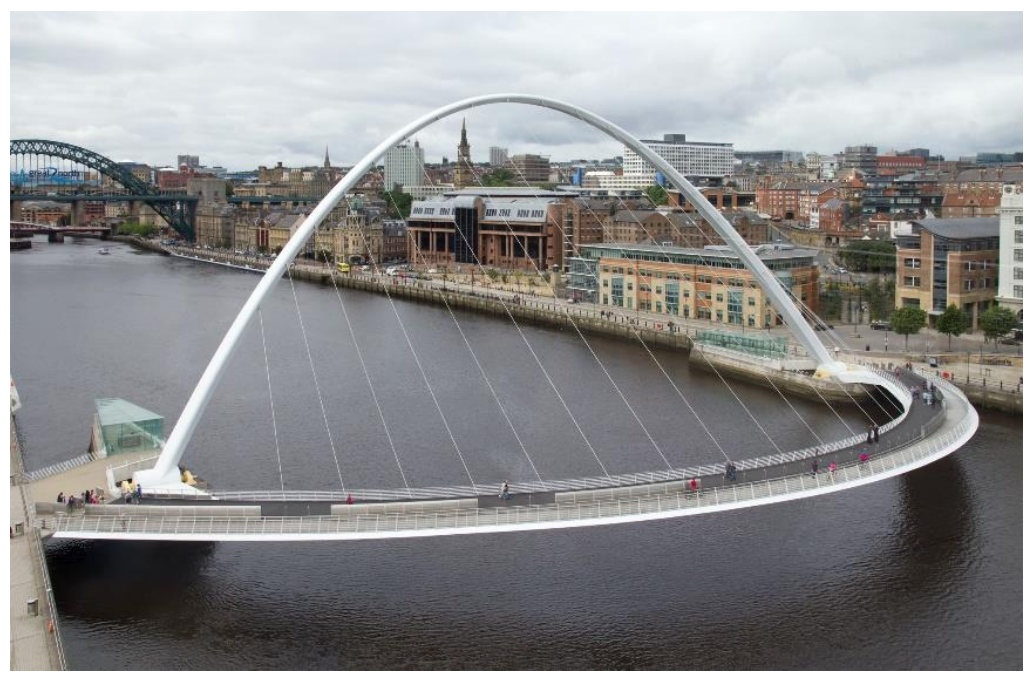

Figure 2. Gateshead Millennium footbridge (Photo: David P. Howard. Creative Commons).

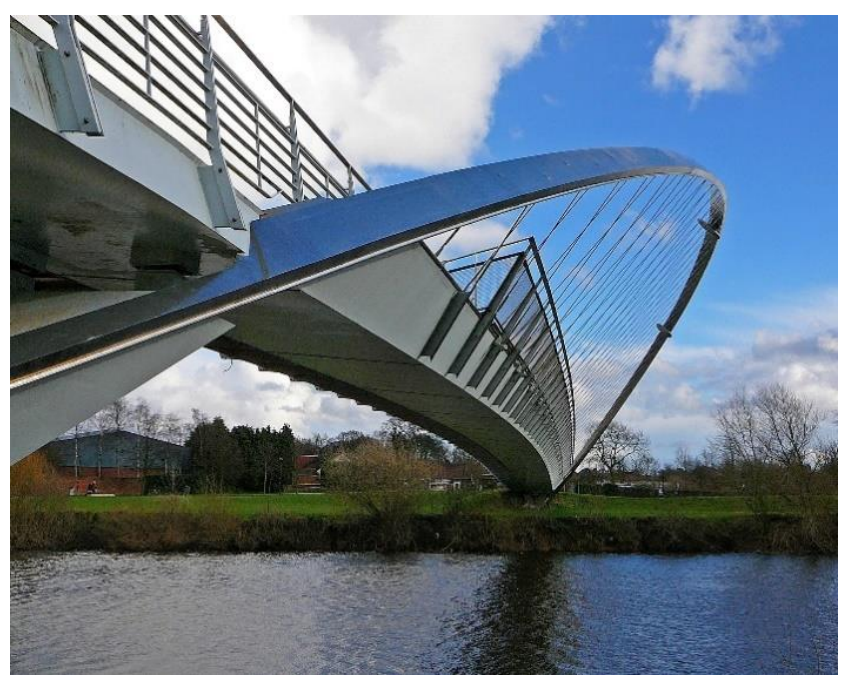

Figure 3. York Millennium footbridge (Photo: Tim Green. Creative Commons). 
In a "classical" vertical planar arch bridge subjected only to in-plane loads, its funicular geometry (which is the geometry that results in an equilibrium state free from bending stresses, i.e., simply under axial forces) is contained within a vertical plane. In these (and other) configurations and for a given load case (usually the permanent loads), the three-dimensional anti-funicular geometry of the arch becomes a warped curve, i.e., it is not contained within a plane such as the arch of the well-known Ripshorst footbridge [10] designed by J. Schlaich (Figure 4).

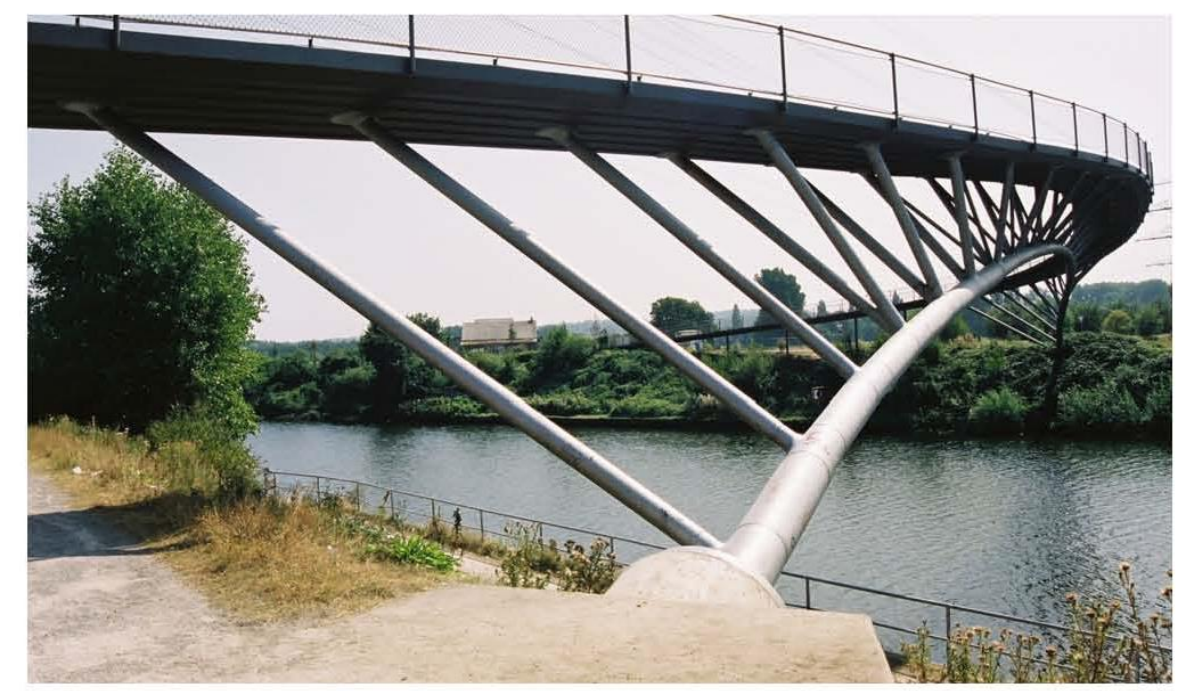

Figure 4. Ripshorst footbridge (Photo courtesy of Nicholas Janberg. structurae.net).

Despite the complex structural behavior and aesthetic potential of this type of bridge, relatively little research has been carried out focused on spatial arch bridges thus far [1,11-13]. This lack of interest for understanding the structural response of this type of bridge is particularly striking when the aesthetic quality of a design, mainly in bridges located in urban environments, becomes more frequently, a desired, or even the primary, objective [14,15]. Similarly, although many research teams are currently carrying out studies that comprehensively explore the full potential of form-finding methods such as the Force Density Method (FDM), Graphic Statics, Thrust Network Analysis or Dynamic Relaxation, the number of studies about anti-funicular geometries in spatial arch bridges is remarkably low. To mention but a few, the work carried out by the teams led by Oschendorf (at the MIT [16]), Adriaenseens (at the Form-Finding Lab at Princeton University [17]), Block (at the Block Research Group at the ETH [18]), and M. Schlaich at SBP [19] are of particular interest. Some of the alternative methods to find the funicular form of arch bridges are the Local Eccentricities Method (LEM) and the Global Reaction Method (GRM), which were both developed by Jorquera-Lucerga and Manterola-Armisén [1,20]; the application of Graphic Statics [21] and the formulation obtained by Beghini et al. [22] by applying the Rankine Theorem. A variation of FDM has been used for form-finding of arches by Lachauer and Block [23]. All of these methods are relatively recent. In fact, Schlaich obtained the warped geometry of the Ripshorst footbridge as the inverted form of a hanging cable [10]. 


\subsection{Validity of the Force Density Method (FDM)}

As a major contribution of this paper, the FDM has been adapted in an innovative and simplified way to find the funicular form of spatial arch bridges. Formulated by Schek [24] in the 1970s, it is one of the most widely used methods for form-finding of prestressed cable-net structures. Full descriptions of the method can be found in Reference [25-27] and more recently in References [28,29]. Since there are other alternative methods than can cope with the most general case such as the studies mentioned above, the need for new form-finding methods may not need to be a priority. However, the FDM is particularly useful in certain cases in which using the LEM or the GRM would have a much higher computational cost. Furthermore, these methods can be freely combined successively to solve the same problem, which affords great freedom and flexibility for the designer.

Additionally, this paper could also be framed within a research line that, somehow, intends to combine the conceptual depth of classic structural methods and the potential of computer-aided design. All the structural analyses have been performed using the SAP 2000 [30] Finite Element Method (FEM) software. In addition, the set of computer programs named SABRINA (which stands for Spatial Arch BRIdges Non-linear Iterative Analysis) originally developed in 2007 [1] by the author have been updated and improved since then to include, among others, the FDM and other methods such as Graphic Statics. These programs are coded in the Matlab language [31] and perform pre-processing, post-processing, and flow control as well as implement the developed algorithms.

\section{Application of the Simplified Force Density Method to Arch Bridges}

The force density method was developed in the 1970s by Schek [23] to find the form of prestressed cable-net structures. However, there are some differences between the original FDM method and the simplified FDM presented in this paper. The most evident difference is that the original FDM addresses the problem of finding the form of a prestressed cable-net structure while the simplified FDM finds the form of a single warped curve. It will be shown how focusing on a single curve leads to significant simplifications in the original formulation.

Another difference is that a cable-net is a tensioned structure while an arch is under compression, which is something irrelevant from a mathematical point of view since the algorithm remains unaffected. However, the fact that the arch is compressed might lead to failure modes associated with compression forces (such as compressive stresses or buckling problems) that are not solved by the form-finding method itself and must be checked inside a general design procedure.

In the original FDM, all the elements are assumed to be only subjected to axial forces pinned at both ends and, within this location, the effect of bending stiffness can be neglected. However, in the adapted method, even though the arch behaves as a bending-free element at the end of the process, these assumptions are no longer true. The form-finding process must cope with the fact that the arch may have clamped ends, which are the most frequent configuration in modern arches. It will be seen that the lack of accuracy associated with this can be counteracted by a set of eccentric fictitious jacks at the springings, which happens in LEM or in GRM $[1,20]$.

The simplified FDM does not make any assumption regarding the behavior of the rest of the structure, i.e., the arch can be linked to elements subjected to bending moments. For example, the structural behavior of the deck [1,2] can be resolved into a planar structural system (behaving as a horizontal arch subjected to axial forces and vertical axis moments) and an out-of-plane structural system (behaving as a curved beam on elastic supports subjected to coupled bending and torsional moments due to the curvature), which is a far more complex behavior than that of a tensioned cable. 


\section{Formulation and Flowchart}

In this section, the formulation for the FDM method [27] is presented and simplified. A flowchart of the practical application of the method is described and discussed.

\subsection{Formulation}

In the original FDM, the equilibrium equations for the node $i\left(x_{i}, y_{i}, z_{i}\right)$ can be written as the formulas below (Figure 5).

$$
\begin{aligned}
& N_{i j} \frac{x_{j}-x_{i}}{L_{i j}}+N_{i k} \frac{x_{k}-x_{i}}{L_{i k}}+N_{i l} \frac{x_{l}-x_{i}}{L_{i l}}+N_{i m} \frac{x_{m}-x_{i}}{L_{i m}}+F_{x i}=0 \\
& N_{i j} \frac{y_{j}-y_{i}}{L_{i j}}+N_{i k} \frac{y_{k}-y_{i}}{L_{i k}}+N_{i l} \frac{y_{l}-y_{i}}{L_{i l}}+N_{i m} \frac{y_{m}-y_{i}}{L_{i m}}+F_{y i}=0 \\
& N_{i j} \frac{z_{j}-z_{i}}{L_{i j}}+N_{i k} \frac{z_{k}-z_{i}}{L_{i k}}+N_{i l} \frac{z_{l}-z_{i}}{L_{i l}}+N_{i m} \frac{z_{m}-z_{i}}{L_{i m}}+F_{z i}=0
\end{aligned}
$$

where, for example, $N_{i j}$ and $L_{i j}$ are, respectively, the axial load and the length of the segment $i-j$.

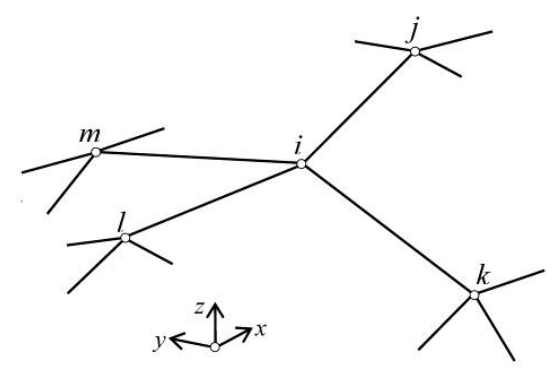

Figure 5. FDM: Node of a cable mesh.

The system of Equations (1)-(3) is non-linear since it depends on the nodes coordinates, which are the solutions for the system. The FDM transforms Equations (1)-(3) into a linear system of equations by forcing the ratio $N / L$ at each segment (i.e., the ratio between the axial force and its length) to be equal to a previously given value $q$ (the so-called force density). Thus, Equations (1)-(3) can be written as the equations below.

$$
\begin{aligned}
& q_{i j} \cdot\left(x_{j}-x_{i}\right)+q_{i k} \cdot\left(x_{k}-x_{i}\right)+q_{i l} \cdot\left(x_{l}-x_{i}\right)+q_{i m} \cdot\left(x_{m}-x_{i}\right)+F_{x i}=0 \\
& q_{i j} \cdot\left(y_{j}-y_{i}\right)+q_{i k} \cdot\left(y_{k}-y_{i}\right)+q_{i l} \cdot\left(y_{l}-y_{i}\right)+q_{i m} \cdot\left(y_{m}-y_{i}\right)+F_{y i}=0 \\
& q_{i j} \cdot\left(z_{j}-z_{i}\right)+q_{i k} \cdot\left(z_{k}-z_{i}\right)+q_{i l} \cdot\left(z_{l}-z_{i}\right)+q_{i m} \cdot\left(z_{m}-z_{i}\right)+F_{z i}=0
\end{aligned}
$$

This original formulation can be adapted to obtain three-dimensional anti-funicular arches for a planar arch bridge contained within the $x-z$ plane (Figure 6). For the intermediate nodes $(2 \leq i \leq n-1)$ located at the given $x_{i}$ abscissae, the vertical equilibrium of every node can be written as the equation below.

$$
\frac{N_{i-1}}{L_{i-1}}\left(z_{i-1}-z_{i}\right)+\frac{N_{i}}{L_{i}}\left(z_{i+1}-z_{i}\right)+F_{z i}=0
$$

where $N_{i}$ and $L_{i}$ are the axial force and the length, respectively, of the segment $i$. Note that, in Equation (7), the previous notation used in cable meshes has been simplified for only one cable/arch by using only one sub-index. The given $z$-coordinates of the 1 and $n$ nodes to complete the system of $n$ linear equations.

$$
\begin{aligned}
& z_{1}=z\left(x_{1}\right) \\
& z_{n}=z\left(x_{n}\right)
\end{aligned}
$$




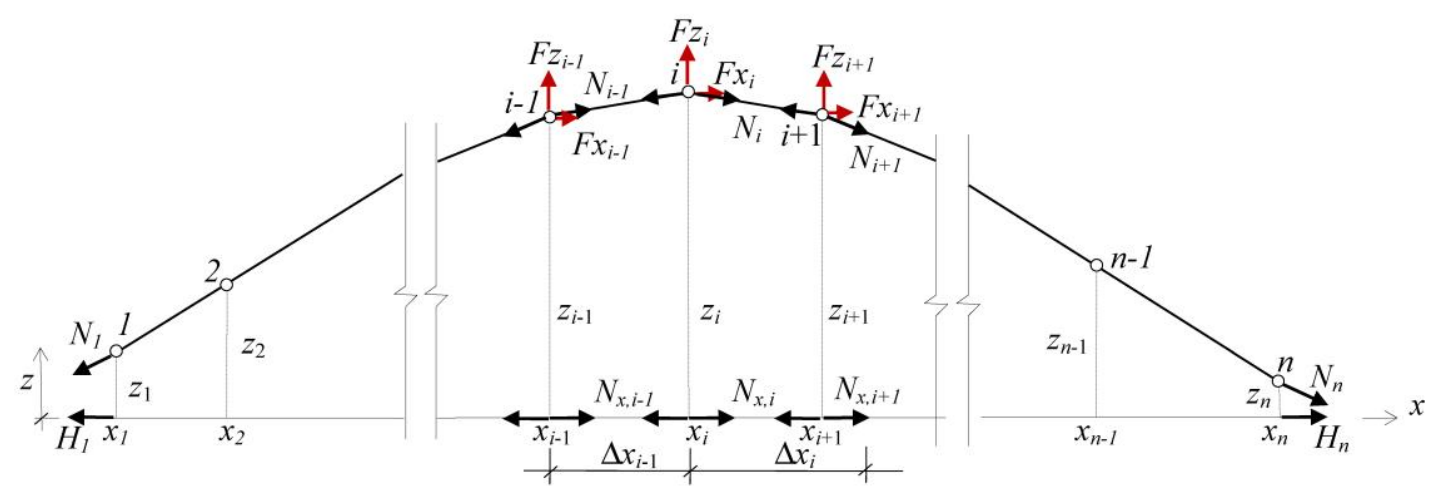

Figure 6. Use of FDM for arch form-finding. Vertical projection.

In our case, the force density $q$ can be expressed as follows.

$$
q_{i} \equiv \frac{N_{i}}{L_{i}}=\frac{N_{x, i}}{\Delta x_{i}}
$$

where $N_{x, i}$ is the longitudinal component (along the $x$-axis) of the axial force of the segment $i$. Since $x_{i}$ are given, $z_{i}$ can be obtained by simply defining $N_{x, i}$. Therefore, Equation (7) transforms into the formula below.

$$
\frac{N_{x, i-1}}{\Delta x_{i-1}} z_{i-1}-\left(\frac{N_{x, i-1}}{\Delta x_{i-1}}+\frac{N_{x, i}}{\Delta x_{i}}\right) \cdot z_{i}+\frac{N_{x, i}}{\Delta x_{i}} z_{i+1}+F_{z i}=0
$$

Similarly to Equations (8), (9), and (11), the equations of equilibrium for the nodes can be written within the $x-y$ plane.

$$
\begin{aligned}
& y_{1}=y\left(x_{1}\right) \\
& y_{n}=y\left(x_{n}\right) \\
& \frac{N_{x, i-1}}{\Delta x_{i-1}} y_{i-1}-\left(\frac{N_{x, i-1}}{\Delta x_{i-1}}+\frac{N_{x, i}}{\Delta x_{i}}\right) \cdot y_{i}+\frac{N_{x, i}}{\Delta x_{i}} y_{i+1}+F_{y i}=0
\end{aligned}
$$

Since both sets of equations (composed of Equations (8), (9), and (11) and Equations (12)-(14)) of equilibrium are uncoupled in the $x-y$ and $x-z$ planes, the location of the nodes $\left(x_{i}, y_{i}, z_{i}\right)$ of the three-dimensional anti-funicular geometry can be obtained by solving two independent systems successively in which each one defines a form contained within a coordinate plane. The spatial procedure is, thus, reduced to two planar procedures which are, nevertheless, related to each other because the values of $N_{x, i}, x_{i}$, and $F_{x i}$ must be the same for both of them. The method will be iterative because the loads that act upon the arch such as the self-weight of the arch, $g_{A}$, or the axial forces at the hangers, $T_{i}$, depend on the geometry of the arch (i.e., the node coordinates), which are the solutions for the system of equations.

The effect of $g_{A}$ can be easily taken into account by assigning an additional load $F z_{i}$ to the given point $i$ equal to the weight of the tributary length of the point (i.e., half the weight of the two segments of arch adjacent to the point $i$ ). A similar procedure can be used to transform a distributed external load into a set of concentrated loads. A strong variation of the load distribution can then be accurately reproduced by simply defining a finer spacing of $x_{i}$.

To express the horizontal equilibrium of the nodes, $n$ more equations should be written. However, this is not necessary in our case if the value of $N_{x}$ is known at only one given node (usually the nodes 1 or $n$, which correspond to the springing points) because, then, $N_{x, i}$ at any point can be evaluated by Equation (15) as shown in Figure 7 and subsequently introduced directly into the systems of equations defined by Equations (8), (9), and (11) and Equations (12)-(14). If $H_{1}$ is given at the node 1 .

$$
N_{x, i}=H_{1}+\sum_{2}^{i} F_{x, i}
$$




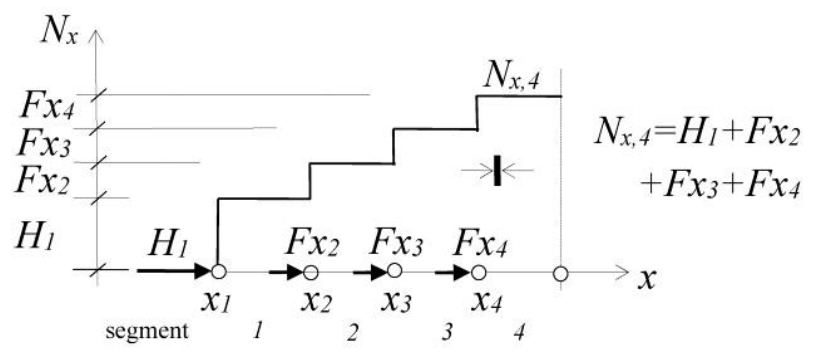

Figure 7. Effect of $F x_{i}$ on $N_{x, i}$

If $\Delta x_{i}=1, q_{i}=N_{x, i}$ (i.e., the force density is equal to the horizontal component of the axial force at the arch). If, additionally, $F x_{i}=0, q_{i}=H_{1}$, i.e., $q_{i}$ is constant and equal to the longitudinal component of the reaction at the springing points, $H_{1}$ (or $H_{n}$ ), which happens, for example, in a vertical plane arch linked to the deck by vertical hangers and subjected only to vertical loads.

When a positive or negative value is given to $H_{1}$, a cable composed of tensioned segments or an arch under compression is obtained, respectively. Strictly speaking, the axial forces $N_{i}$ can change its sign depending on the values of $F x_{i}$ and a compression-only shape might transform into a tension-only shape. However, these structural configurations are not frequent in engineering.

For a given set of external loads, there is one unique anti-funicular shape for each value of $H$ (i.e., there is an infinite number of anti-funicular geometries for a given set of loads). In a 2-D process, the arch can be forced to pass through a given point $\left(x_{C}, z_{C}\right)$ by adjusting the value of $H$. However, for a given $x_{C}$, the 3-D shape cannot be forced to pass through a given point $C\left(x_{C}, y_{C}, z_{C}\right)$ : when $H$ is obtained with the aim of forcing the $z$-coordinate of the point $C, z\left(x_{C}\right)$, to be equal to a given value $z_{C}$, the $y$-coordinate of $C$ cannot be chosen and is a result of the process. Likewise, the same happens to $z_{C}$ when $y_{C}$ is given. Thus, the value of only one more coordinate either $y_{C}$ or $z_{C}$ can be imposed for a given $x_{C}$. In this paper, the anti-funicular shapes have generally been forced to pass through the crown of the arch, $C$, at $x_{C}=0$, which is defined by its z-coordinate, $z_{C}$.

\subsection{Flow Chart}

Figure 8 shows the flow chart of the process. In short, the flow chart shows how the geometry of the arch is obtained iteratively as a function of its self-weight $g_{A}$ and the concentrated loads transmitted by the hangers, $T_{i}$. The actions at the hangers can be obtained in two alternative ways depending whether non-linearity is considered or not (steps $a$ and $b$ of the flowchart). In the simplest case described in Figure 9, the deck is assumed to behave as a simply supported continuous girder. An auxiliary FEM model of only the deck is needed, which is supported at the locations of the anchorages of the hangers. The axial loads at the hangers $T_{i}$ can be calculated because their vertical components are equal to the vertical reactions $R z_{i}$ at the supported nodes of the auxiliary FEM model. The calculations of $R z_{i}$, i.e., the output of the FEM model, is needed only in the first iteration because they remain unchanged during the iterative process. However, when non-linearity is considered, the auxiliary FEM model must include the whole structure (deck, arch, and hangers) and the axial loads must be obtained from the output of the FEM calculation at every iteration because this model must be redefined at each iteration as the geometry of the arch changes. 


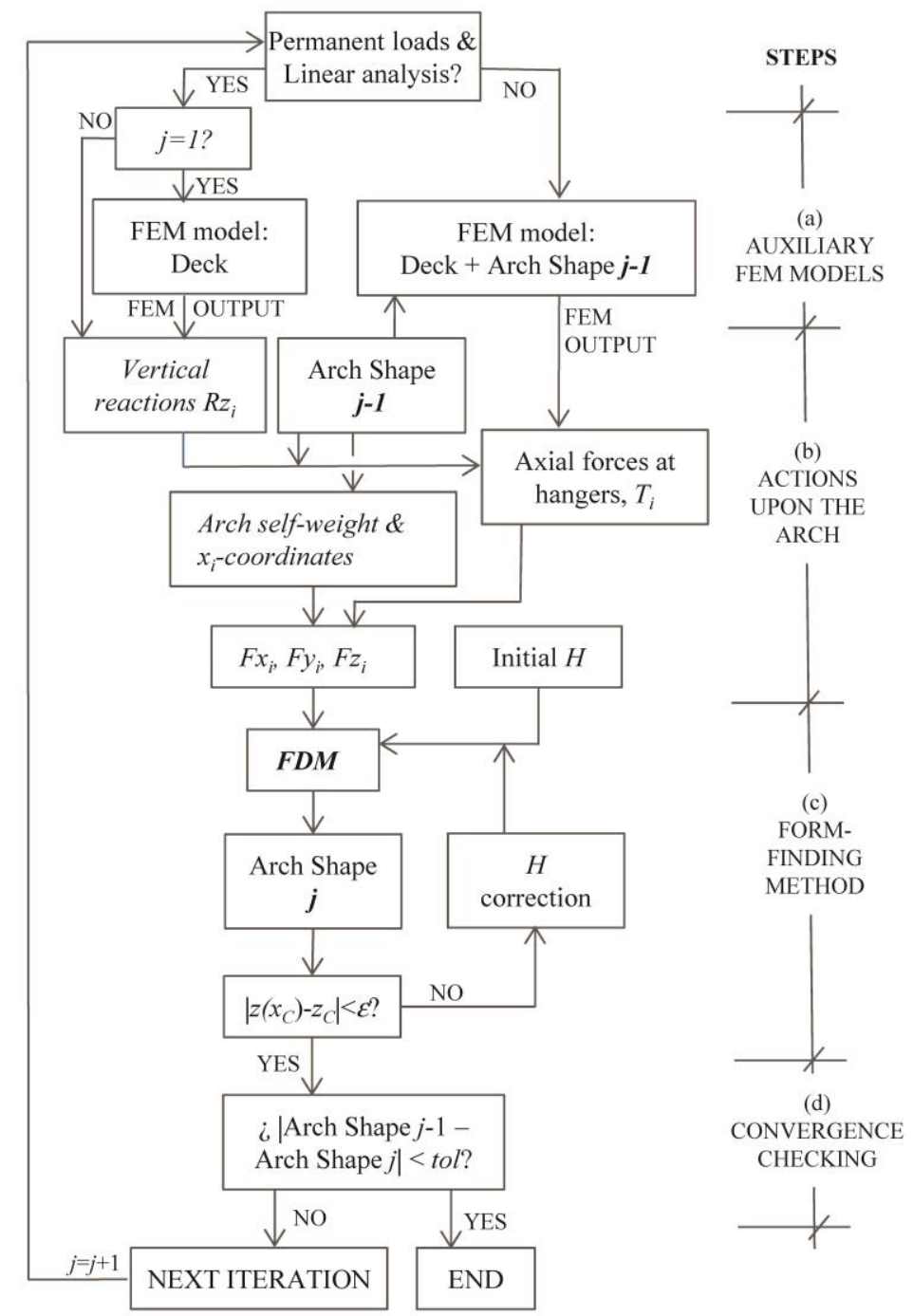

Figure 8. Simplified Forced Density Method: Flow chart.
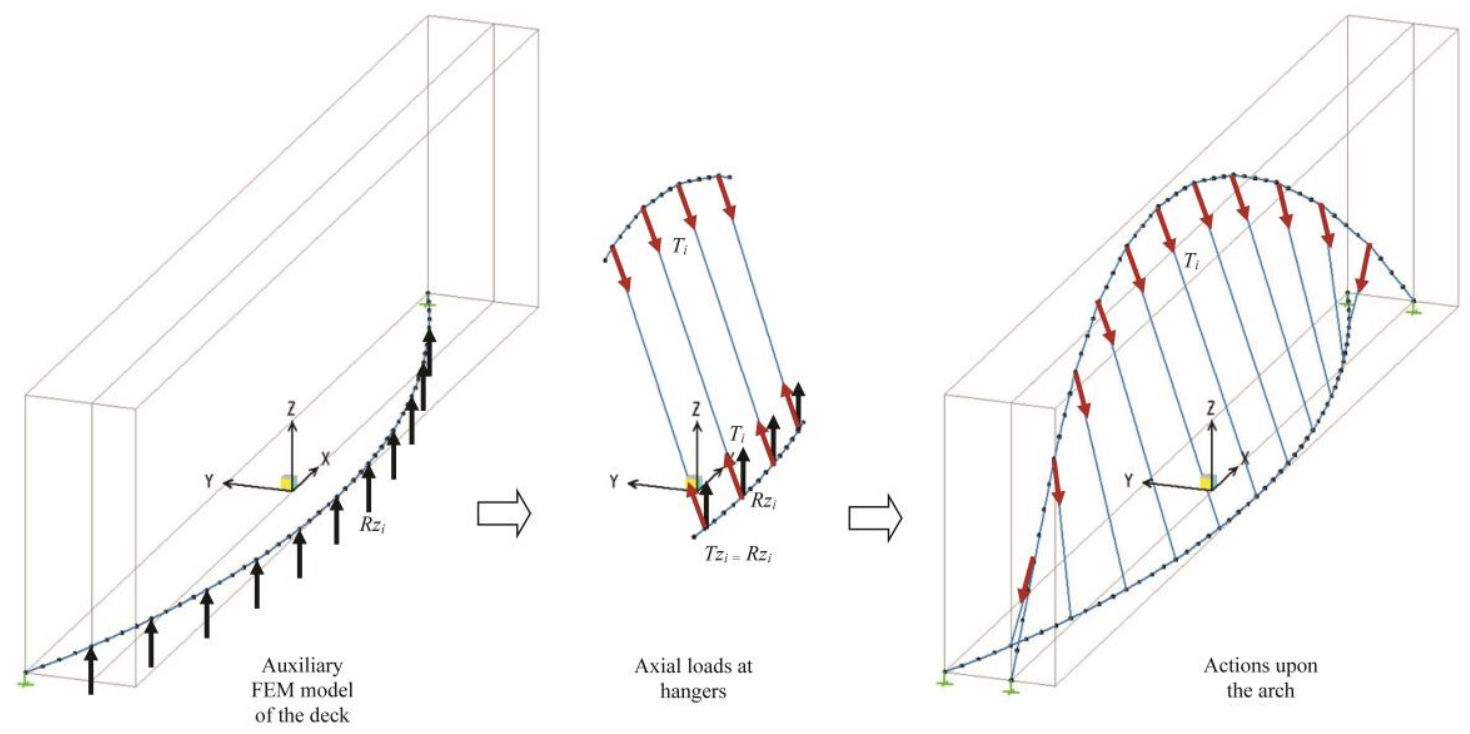

Figure 9. Actions upon the arch transferred by hangers. 
The additional effect of the self-weight of the arch is easily considered by assigning an additional load $F z_{i}$ at every point $i$ of the arch equal to the weight of its tributary length of arch.

Once the actions are determined, the form-finding formulation defined in Section 3.1 is applied. The form-finding algorithm (step c of flowchart) is iterative because the value of $H$ (horizontal reaction at one springing of the arch) must be successively corrected in order to make the centroidal line of the arch pass through a given point $\left(x_{C}, z_{C}\right)$ with an convergence error smaller than $\varepsilon$.

The process ends (i.e., the convergence is achieved, step $d$ of the flowchart) when the difference between all the coordinates of the nodes of two successive iterations of the arch's geometry (Shapes $j$ and $j-1$ ) is smaller than a tolerance tol previously defined. Figure 10 illustrates this iterative process including only the hangers corresponding to the last iteration.

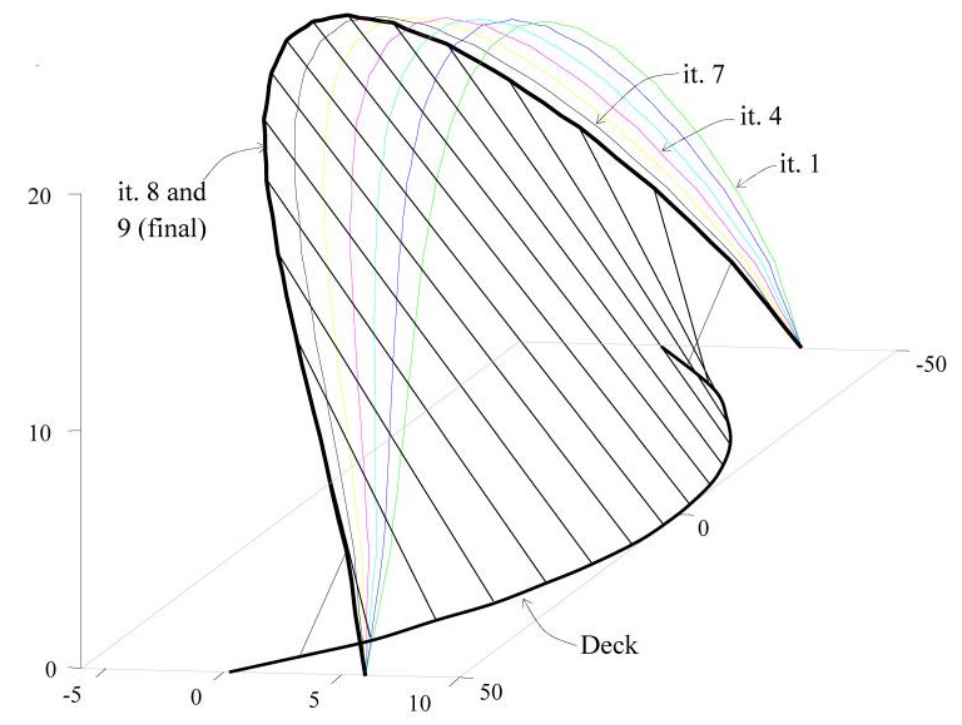

Figure 10. Iterative form-finding (m) by application of the Simplified FDM.

\section{Discussion of the Simplified FDM}

Clearly, the method provides identical results to other methods such as the LEM or the GRM. Compared to these, a very important feature of the FDM (either simplified or in its original formulation) is that it obtains the final anti-funicular form from a set of known external loads acting upon the arch. It cannot be applied to refine a given geometry such as with a known bending moment diagram because the input data for the algorithms are the external loads and not the internal forces. By contrast, both the LEM and the GRM, which correct the position of each point depending on the value of its internal forces, as shown in References [1,20], are very effective in refining the geometry of an arch with known but undesired bending moments. An example of its use is the refining of the polygonal geometry of the twin leaning arches of the Urnieta bridge [32] in Spain. Thus, the method to be used depends on the data known.

Another very important aspect is that, regardless of the method used, it is clearly necessary to know the input data needed in every iteration. In the case of the FDM, the input data will be the loads acting upon the arch, $F_{i}$. As it has been previously shown, these loads are easily evaluated when the load case for which the anti-funicular geometry is obtained coincides with the permanent loads since the vertical components $T_{z i}$ of the hangers axial forces, $T_{i}$, coincide with the vertical reactions, $R_{z i}$, of a simply supported deck and do not change between iterations. In this case, the FDM is recommended since the FEM auxiliary model only needs to reproduce the simply supported deck and the method is significantly faster than the LEM or GRM. However, when the anti-funicular geometry is obtained for a load case that does not coincide with the permanent loads or when non-linearity is to be considered, $T_{i}$ depends on the whole structure and it obtains a new model at each iteration. In these cases, using any of the three mentioned methods leads to a similar computational cost. 
An additional advantage is that different methods can be combined throughout the design process. If the FDM is used as a fast way to obtain a funicular form, either the LEM or the GRM can be applied at a later step. They can be suitable not only for refining the geometry but also for obtaining the magnitude of the forces to be introduced by jacks acting at the springings or at the crown, as a final stage of the erection of the arch. The effect of the jacks is shown in Section 5. Detailed flowcharts for LEM and GRM can be found in Reference [20].

\section{Case studies: Examples of Application}

To illustrate the capabilities of the simplified FDM described above, the funicular geometry has been obtained for four case studies, A to D. The study has been carried out mainly to show the effect of different geometrical configurations and, consequently, the same reference bridge with equal mechanical parameters has been considered for all cases. The reference model (Figure 11) is an all-steel arch bridge spanning $L=100 \mathrm{~m}$. The cross section of the arch is a circular hollow section (CHS) with $\phi=1000 \mathrm{~mm}$ and thickness $t=30 \mathrm{~mm}$. The cross section of the deck is a $4000 \times 1000 \mathrm{~mm}$ rectangular hollow section (RHS) with a thickness $t_{f}=t_{w}=15 \mathrm{~mm}$. The springing points of the arch are clamped while the deck is simply supported at the abutments. Apart from the self-weight of the arch and the deck, $g_{A}$ and $g_{D}$, respectively, the bridge is assumed to be subjected to a dead load acting downwards, $g_{D L}$, of $-12 \mathrm{kN} / \mathrm{m}$.

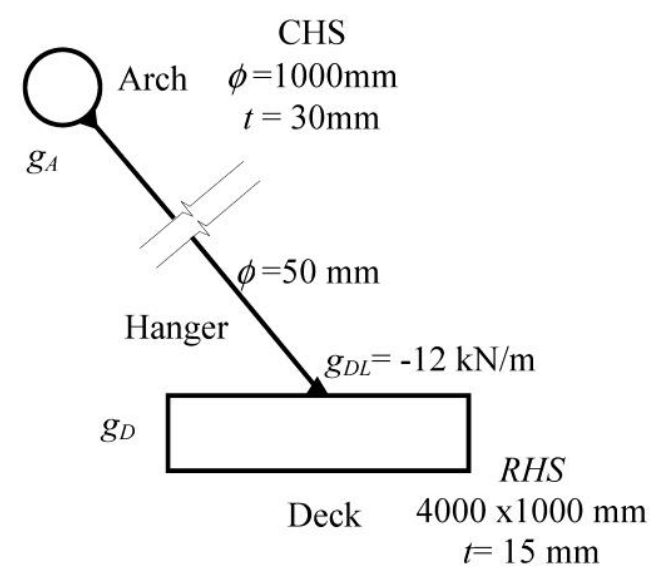

Figure 11. Reference bridge: cross-section and loads considered.

The models A and B (Figure 12) correspond to symmetrical curved decks with horizontal sag of $10 \mathrm{~m}$. The arch of the model $\mathrm{A}$ is also symmetrical and the coordinates of the springing points are $( \pm 50,6,0)$ while the arch of the model $B$ is non-symmetrical and the coordinates of its springing points are $(-50,5,-3)$ and $(50,2,8)$. The decks $C$ and $D$ (Figure 13) are symmetrical with respect to the origin of coordinates, which also illustrates the aesthetical potential of this type of structure. Deck $C$ is straight while deck D is an S-shaped deck composed of two half-waves with a horizontal sag of $10 \mathrm{~m}$ among each one. An S-shaped deck similar to this one has been proposed by Schlaich [14,19]. 

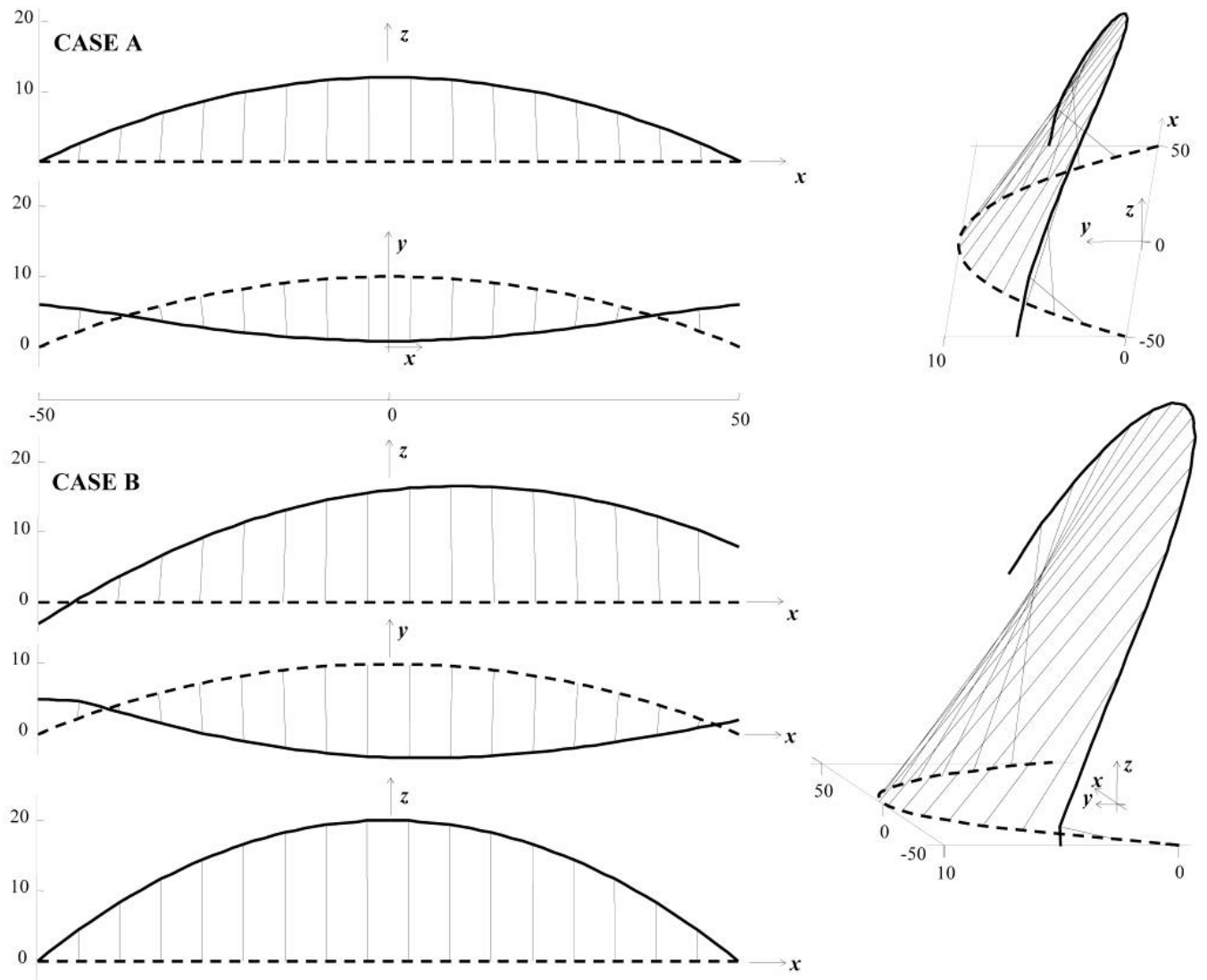

Figure 12. Case studies A and B. Anti-funicular geometry (m): Elevation, plan, and perspective views.
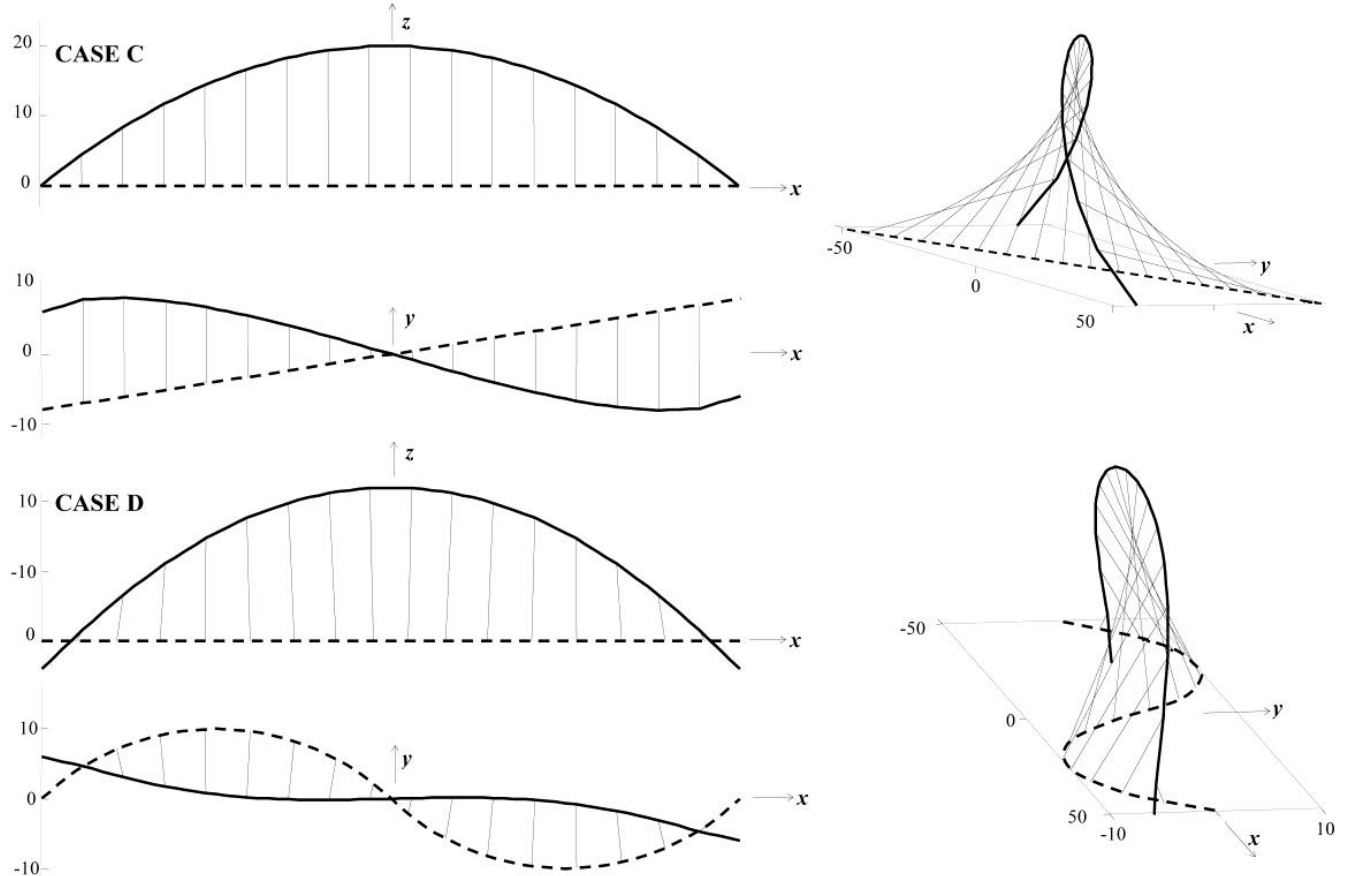

Figure 13. Case studies C and D. Anti-funicular geometry (m): Elevation, plan, and perspective views.

Figure 14 shows the bending moments at the bridge defined in the case study A. The FDM is based on cable structures, a type of structure that is usually assumed to be simply supported at the springing points and made out of a material of infinite axial stiffness. Because the arch of the case study A is, in fact, made of steel and clamped at the springing points, bending moments due to axial 
shortening of the arch appear and the bending moments at the arch are not equal to zero. For the axial force at the crown of the arch shown in Figure 14, which is equal to $-3202 \mathrm{kN}$, the eccentricity of $M_{y}$ and $M_{z}$ are, respectively, 30 and $16 \mathrm{~mm}$ at the crown for a $1000 \mathrm{~mm}$-diameter pipe.

Although these results can be considered excellent because their accuracy is smaller than the erection tolerance, the results can be refined even further by using jacks at the springing points to set the bending moments $M_{y}$ and $M_{z}$ at the springings and the $M_{y}$ moment at the crown to zero. The results from this process are shown in Figure 14. For this case, the axial forces at the arch $\mathrm{N}$ at the crown and at the springings are equal to $-3225 \mathrm{kN}$ and to $-3627 \mathrm{kN}$, respectively. Therefore, after refining the results, the maximum eccentricity of the resultant of the axial forces at any point of the arch is roughly $2 / 3125$, which is $0.6 \mathrm{~mm}$. This value is much smaller than the one obtained before using jacks.

For the GRM and LEM, these accurate results are directly obtained as a part of the process itself since both methods use jacks for setting the bending moments at the selected degrees of freedom of the chosen points to zero before correcting the geometry, as detailed in Reference [1] or Reference [20].

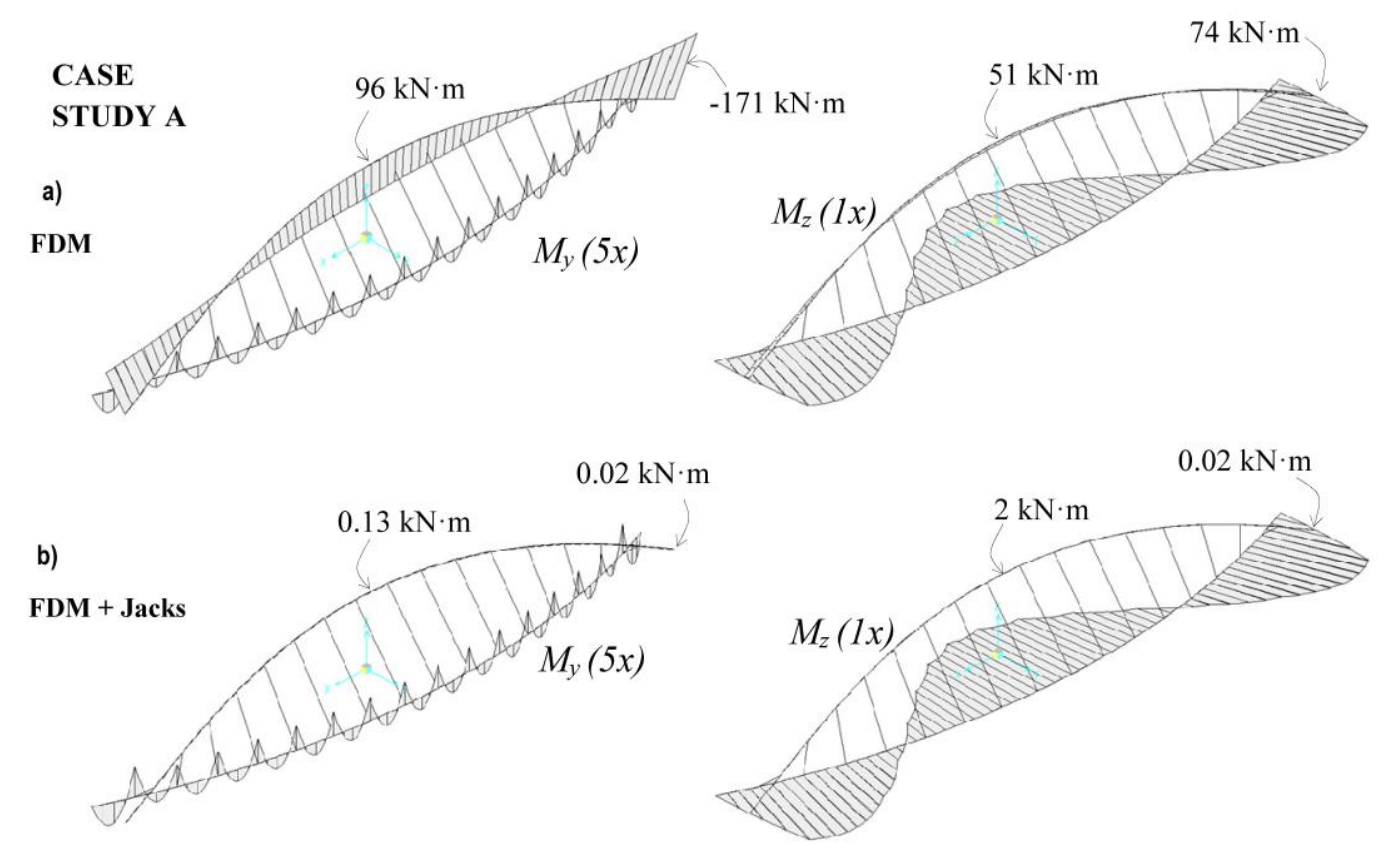

Figure 14. Bending moment at bridge for the case study A: (a) Results of FDM or SGSM. (b) Results of FDM + Jacks acting on springing points (or, alternatively, results of LEM or GRM).

\section{Conclusions}

The paper shows how a form-finding method known as the simplified Force Density Method originally developed for cable structures can be adapted to obtain three-dimensional anti-funicular arches either because of functional requirements, structural efficiency, or due to aesthetical purposes.

A detailed formulation and a flowchart of the method are described and discussed.

The paper also shows how this method, in the formulation presented (or slightly modified), allow the designer to cope with virtually every possibility in usual design tasks of spatial arch bridges such as highly non-symmetrical bridges or when non-linear behavior must be considered.

The simplified FDM is an alternative method to other methods such as the GRM and the LEM and is especially suitable when the anti-funicular geometry is found for permanent loads and linear analysis can be considered.

The paper shows the high aesthetical potential of this type of structure. 
Funding: The author wishes to thank the Technical University of Cartagena (UPCT, Spain) for the funding provided through the research project 2007_2420.

Conflicts of Interest: The author declares no conflict of interest. The funders had no role in the design of the study, in the collection, analyses, or interpretation of data, in the writing of the manuscript, or in the decision to publish the results.

\section{References}

1. Jorquera-Lucerga, J.J. Estudio del Comportamiento Resistente de los Puentes Arco Espaciales (A Study on the Structural Behaviour of Spatial Arch Bridges). Ph.D. Thesis, Technical University of Madrid (UPM), Madrid, Spain, 2007. Available online: http:/ / oa.upm.es/812/1/JUAN_JOSE_JORQUERA_LUCERGA.pdf (accessed on 7 February 2007). (In Spanish)

2. Jorquera-Lucerga, J.J. Structural behaviour of spatial arch bridges. In Proceedings of the IASS Symposium on Evolution and Trends in Design, Analysis and Construction of Shell and Spatial Structures, Valencia, Spain, 28 September-2 October 2009.

3. Billington, D.P. Robert's Maillart's Bridges: The Art of Engineering; Princeton University Press: Princeton, NJ, USA, 1979.

4. Laffranchi, M.; Marti, P. Robert’s Maillart’s concrete arch bridges. J. Struct. Eng. 1997, 123, 1280-1286. [CrossRef]

5. Hussain, N.; Wilson, I. The Hulme Arch Bridge, Manchester. In Proceedings of the ICE-Civil Engineering, London, UK, February 1999; Volume 132, pp. 2-13. Available online: https://trid.trb.org/view/499313 (accessed on 10 December 2018).

6. Johnson, J.; Curran, P. Gateshead Millennium Bridge-An eye-opener for engineering. In Proceedings of the ICE-Civil Engineering, London, UK, February 2003; Volume 156, pp. 16-24. Available online: https: / / www.icevirtuallibrary.com/doi/abs/10.1680/cien.2003.156.1.16 (accessed on 25 May 2015).

7. Mairs, D. York Millennium Bridge-A footbridge with an inclined arch, UK. Struct. Eng. Int. 2001, 3, $172-174$. [CrossRef]

8. Tzonis, A.; Caso, R. Santiago Calatrava: The Bridges; Thames \& Hudson: London, UK, 2005.

9. Tarquis Alfonso, F.; Hue Ibargüen, P. Juscelino Kubitschek Bridge. In Proceedings of the III ACHE Conference, Zaragoza, Spain, 14-17 November 2005. (In Spanish)

10. Schlaich, J.; Moschner, T. Die Ripshorsterbrücke über den Rheine-Herne-Kanal. (The Ripshorst Bridge over the Rhine-Herne Canal.) Bautechnik 1999, 76, 459-462. (In German)

11. Sarmiento-Comesías, M. Structural Behaviour and Design Criteria of Spatial Arch Bridges. Ph.D. Thesis, Technical University of Catalonia, Barcelona, Spain, 2015.

12. Hudecek, M. Structural Behaviour of Spatial Arch Bridges. Ph.D. Thesis, University of Calgary, Calgary, AB, Canada, 2017.

13. García-Guerrero. El Puente Arco Espacial Como una Evolución Tipológica (The Spatial Arch Bridge as a Typological Evolution). Ph.D. Thesis, Technical University of Cartagena, Cartagena, Spain, 2018. (In Spanish)

14. Baus, U.; Schlaich, M. Footbridges, Construction, Design, History; Birkhäuser, Verlag: Basel, Switzerland, 2008.

15. Strasky, J. Stress Ribbon and Cable-Supported Pedestrian Bridges, 2nd ed.; ICE Publishing: Westminster, London, UK, 2011.

16. Masonry at MIT. Available online: http:/ / web.mit.edu/masonry/ (accessed on 10 September 2018).

17. Form-Finding Lab at Princeton University. Available online: http://formfindinglab.princeton.edu/ (accessed on 10 September 2018).

18. Block Research Group. Available online: http:/ /block.arch.ethz.ch/ (accessed on 10 September 2018).

19. Schlaich, M.; Bleichar, A.; Nier, M. Die Weinbergbrücke in Rathenow. (The Weinberg Bridge in Rathenow). Bauingenieur 2016, 91, 71-80. (In German)

20. Jorquera-Lucerga, J.J.; Manterola-Armisén, J. An iterative form-finding method for antifunicular shapes in spatial arch bridges. Comput. Struct. 2012, 108-109, 42-60. [CrossRef]

21. Jorquera-Lucerga, J.J. Three-dimensional antifunicular geometries in spatial arch bridges. In Proceedings of the 37th IABSE Symposium, Madrid, Spain, 3-5 September 2014.

22. Beghini, A.; Beghini, L.L.; Schultz, J.A.; Carrion, J.; Baker, W.F. Rankine's theorem for the design of cable structures. Struct. Multidiscip. Optim. 2013, 48, 877-892. [CrossRef] 
23. Lachauer, L.; Block, P. Interactive Equilibrium Modelling. Int. J. Space Struct. 2014, 29, 25-37. [CrossRef]

24. Schek, H.J. The force density method for form-finding and computation of general networks. Comput. Methods Appl. Mech. Eng. 1974, 3, 115-134. [CrossRef]

25. Lewis, W. Tension Structures Form and Behavior; Thomas Telford: London, UK, 2003.

26. Buchholdt, H.A. An Introduction to Cable Roof Structures, 2nd ed.; Thomas Telford: London, UK, 1985.

27. Tibert, G. Numerical Analyses of Cable Roof Structures. Ph.D. Thesis, KTH, Stockholm, Sweden, 1999.

28. Asadi HHariri-Ardebili, M.A.; Mirtaheri, M.; Zandi, A.P. Force density ratios of flexible borders to membrane in tension fabric structures. Struct. Eng. Mech. 2018, 67, 555-563. [CrossRef]

29. Adriaenssens SBlock, P.; Veenendaal, D.; Williams, C. Shell Structures for Architecture: Form Finding and Optimization; Routledge: Abingdon, UK, 2014.

30. Computers \& Structures Inc. SAP 2000 Analysis Reference Manual; CSI: Berkeley, CA, USA, 1998.

31. The Mathworks Inc. Matlab: The Language of Technical Computing; Release 7.6 Reference Manual; The Mathworks Inc.: Natick, MA, USA, 2012.

32. Romo-Martín, J.; Jorquera-Lucerga, J.J. Puente arco sobre la variante GI-131 en Urnieta (Arch bridge over the GI-131 road in Urnieta). In Proceedings of the ACHE V. Conference, Barcelona, Spain, 25-27 October 2011. (In Spanish)

(C) 2018 by the author. Licensee MDPI, Basel, Switzerland. This article is an open access article distributed under the terms and conditions of the Creative Commons Attribution (CC BY) license (http://creativecommons.org/licenses/by/4.0/). 